\title{
The hypocretin/orexin antagonist almorexant promotes sleep without impairment of performance in rats
}

\author{
Stephen R. Morairty ${ }^{1}{ }^{*}$, Alan J. Wilk ${ }^{1}$, Webster U. Lincoln ${ }^{1}$, Thomas C. Neylan ${ }^{2}$ and Thomas S. Kilduff ${ }^{1}$ \\ 1 SRI International, Center for Neuroscience, Biosciences Division, Menlo Park, CA, USA \\ ${ }^{2}$ Department of Psychiatry, SF VA Medical Center/NCIRE/University of California, San Francisco, CA, USA
}

Edited by:

Christopher J. Winrow, Merck, USA

Reviewed by:

Collin Park, University of South

Florida, USA

Michihiro Mieda, Kanazawa

University, Japan

\section{${ }^{*}$ Correspondence:}

Stephen R. Morairty, SRI

International, 333 Ravenswood Ave.,

Menlo Park, CA, USA

e-mail: stephen.morairty@sri.com
The hypocretin receptor (HcrtR) antagonist almorexant (ALM) has potent hypnotic actions but little is known about neurocognitive performance in the presence of ALM. HcrtR antagonists are hypothesized to induce sleep by disfacilitation of wake-promoting systems whereas $\mathrm{GABA}_{\mathrm{A}}$ receptor modulators such as zolpidem (ZOL) induce sleep through general inhibition of neural activity. To test the hypothesis that less functional impairment results from HcrtR antagonist-induced sleep, we evaluated the performance of rats in the Morris Water Maze in the presence of ALM vs. ZOL. Performance in spatial reference memory (SRM) and spatial working memory (SWM) tasks were assessed during the dark period after equipotent sleep-promoting doses $(100 \mathrm{mg} / \mathrm{kg}, \mathrm{po})$ following undisturbed and sleep deprivation (SD) conditions. ALM-treated rats were indistinguishable from vehicle (VEH)-treated rats for all SRM performance measures (distance traveled, latency to enter, time within, and number of entries into, the target quadrant) after both the undisturbed and $6 \mathrm{~h}$ SD conditions. In contrast, rats administered ZOL showed impairments in all parameters measured compared to VEH or ALM in the undisturbed conditions. Following $\mathrm{SD}, \mathrm{ZOL}$-treated rats also showed impairments in all measures. ALM-treated rats were similar to VEH-treated rats for all SWM measures (velocity, time to locate the platform and success rate at finding the platform within $60 \mathrm{~s}$ ) after both the undisturbed and SD conditions. In contrast, ZOL-treated rats showed impairments in velocity and in the time to locate the platform. Importantly, ZOL rats only completed the task $23-50 \%$ of the time while ALM and VEH rats completed the task $79-100 \%$ of the time. Thus, following equipotent sleep-promoting doses, ZOL impaired rats in both memory tasks while ALM rats performed at levels comparable to $\mathrm{VEH}$ rats. These results are consistent with the hypothesis that less impairment results from $\mathrm{HcrtR}$ antagonism than from $\mathrm{GABA}_{A}$-induced inhibition.

Keywords: hypocretins/orexins, cognitive impairment, memory impairment, hypnotics, water maze, spatial reference memory, spatial working memory, EEG

\section{INTRODUCTION}

Insomnia is a highly prevalent condition affecting $10-30 \%$ of the general population; (NIH, 2005; Roth, 2007; Mai and Buysse, 2008). Sleep loss and sleep disruption can lead to a degradation of neurocognitive performance as assessed by objective and subjective measures (Wesensten et al., 1999; Belenky et al., 2003; Lamond et al., 2007). Prescription sleep medications are often used to treat insomnia and obtain desired amounts of sleep. Presently, nonbenzodiazepine, positive allosteric modulators of the $\mathrm{GABA}_{\mathrm{A}}$ receptor such as zolpidem (ZOL) are the most widely prescribed hypnotic medications. Although known to induce sleep, these compounds have been shown to significantly impair psychomotor and memory functions in rodents (Huang et al., 2010; Uslaner et al., 2013; Zanin et al., 2013), non-human primates (Makaron et al., 2013; Soto et al., 2013; Uslaner et al., 2013) and humans (Balkin et al., 1992; Wesensten et al., 1996, 2005; Mattila et al., 1998; Mintzer and Griffiths, 1999; Verster et al., 2002; Storm et al., 2007; Otmani et al., 2008; Gunja, 2013). Such impairment can be particularly troubling when there is an urgent need for highly functional performance in the presence of drug such as with first responders, military personnel, and caregivers. Further, complex behaviors during the sleep period (e.g., eating, cooking, driving, conversations, sex) have been associated with these medications (Dolder and Nelson, 2008). Therefore, more effective hypnotics are needed that facilitate sleep that is easily reversible in the event of an unexpected awakening that demands unimpaired cognitive and psychomotor performance.

Recently, antagonism of the hypocretin (Hcrt; also called orexin) receptors has been identified as a target mechanism for the next generation of sleep medications (Brisbare-Roch et al., 2007; Dugovic et al., 2009; Whitman et al., 2009; Hoever et al., 2010, 2012a,b; Coleman et al., 2012; Herring et al., 2012; Winrow et al., 2012; Betschart et al., 2013). The Hcrt system is well known to play an important role in the maintenance of wakefulness (de Lecea, 2012; Inutsuka and Yamanaka, 2013; Mieda and Sakurai, 2013; Saper, 2013). Hcrt fibers project throughout the central nervous system (CNS), with particularly dense projections and receptor expression found in arousal centers including the locus 
coeruleus, the tuberomammilary nucleus, dorsal raphe nuclei, laterodorsal tegmentum, pedunculopontine tegmentum, and the basal forebrain (Peyron et al., 1998; Marcus et al., 2001). The excitatory effects of the Hcrt peptides on these arousal centers is hypothesized to stabilize and maintain wakefulness. Therefore, blockade of the Hcrt system should disfacilitate these arousal centers, creating conditions that are permissive for sleep to occur.

The current study tests the hypothesis that the dual Hcrt receptor antagonist almorexant (ALM) produces less functional impairment than ZOL. The rationale that underlies this hypothesis is that ZOL causes a general inhibition of neural activity whereas ALM specifically disfacilitates wake-promoting systems. We tested this hypothesis using tests of spatial reference memory (SRM) and spatial working memory (SWM) in the Morris Water Maze. Although the concentrations of ALM and ZOL administered prior to these tests were equipotent in hypnotic efficacy, the performance of rats treated with ALM were superior to that of rats treated with $\mathrm{ZOL}$.

\section{MATERIALS AND METHODS ANIMALS}

One hundred fifty three male Sprague Dawley rats (300g at time of purchase; Charles River, Wilmington, MA) were distributed among the 12 groups as described in Table 1. All animals were individually housed in temperature-controlled recording chambers $\left(22 \pm 2{ }^{\circ} \mathrm{C}, 50 \pm 25 \%\right.$ relative humidity) under a 12:12 light/dark cycle with food and water available ad libitum. All experimental procedures were approved by SRI International's Institutional Animal Care and Use Committee and were in accordance with National Institute of Health (NIH) guidelines.

\section{SURGICAL PROCEDURES}

Rats were instrumented with sterile telemetry transmitters (F40EET, Data Sciences Inc., St Paul, MN) as previously described (Morairty et al., 2008, 2012; Revel et al., 2012, 2013). Briefly, under isoflurane anesthesia, transmitters were placed intraperitoneally and biopotential leads were routed subcutaneously to the head and neck. Holes were drilled into the skull at $1.5 \mathrm{~mm}$ anterior to bregma and $1.5 \mathrm{~mm}$ lateral to midline, and $6 \mathrm{~mm}$ posterior to bregma and $4 \mathrm{~mm}$ lateral to midline on the right hemisphere. Two biopotential leads used as EEG electrodes were inserted into the holes and affixed to the skull with dental acrylic. Two biopotential leads used as EMG electrodes were positioned bilaterally through the nuchal muscles.

\section{IDENTIFICATION OF SLEEP/WAKE STATES}

After at least 3 weeks post-surgical recovery, EEG, and EMG were recorded via telemetry using DQ ART 4.1 software (Data Sciences

Table 1 | The number of rats tested for each of the 12 experimental groups.

\begin{tabular}{lcccccccc}
\hline \multirow{2}{*}{ Test } & \multicolumn{3}{c}{ No SD } & & \multicolumn{3}{c}{$\mathbf{6 h}$ SD } \\
\cline { 2 - 4 } \cline { 8 - 9 } & VEH & ALM & ZOL & & VEH & ALM & ZOL \\
\hline Reference memory & 14 & 13 & 17 & & 16 & 16 & 8 \\
Working memory & 11 & 12 & 12 & & 12 & 11 & 11
\end{tabular}

Inc., St Paul, MN). Following completion of data collection, the EEG, and EMG recordings were scored in $10 \mathrm{~s}$ epochs as waking $(\mathrm{W})$, rapid eye movement sleep (REM), or non-rapid eye movement sleep (NREM) by expert scorers blinded to the treatments using NeuroScore software (Data Sciences Inc., St Paul, MN). Sleep latency was defined as the first $60 \mathrm{~s}$ of continuous sleep following drug administration. Recordings were started at Zeitgeber time (ZT) 12 (lights off) and continued until animals performed the water maze tests.

\section{SLEEP DEPRIVATION PROCEDURES}

Animals were sleep deprived (SD) from ZT12-18 by progressive manual stimulation concurrent with EEG and EMG recording. The rats were continuously observed and, when they appeared to attempt to sleep, progressive interventions were employed to keep them awake: removal of cage tops, tapping on cages, placement of brushes inside the cage, or stroking of vibrissae or fur with an artist's brush.

\section{DRUGS}

Almorexant (ALM; ACT-078573), was synthesized at SRI International (Menlo Park, CA. USA) according to the patent literature. Zolpidem (ZOL) was a gift from Actelion Pharmaceuticals Ltd. For the SWM task, rats were dosed with ALM (100 mg/kg, p.o.), ZOL (100 mg/kg, p.o.) or vehicle (VEH; $1.25 \%$ hydroxypropyl methyl cellulose, $0.1 \%$ dioctyl sodium sulfosuccinate, and $0.25 \%$ methyl cellulose in water) at ZT18 and left undisturbed until time to perform memory tasks (see below). For the SRM task, most rats were also administered ALM, ZOL, and VEH p.o. at the concentrations above. However, one cohort of rats was administered drugs i.p. For these rats, ALM was administered at $100 \mathrm{mg} / \mathrm{kg}(N=6), \mathrm{ZOL}$ at $30 \mathrm{mg} / \mathrm{kg}(N=8)$ and VEH $(N=7)$. ZOL is approximately $3 \mathrm{X}$ more potent i.p. than p.o.(Vanover et al., 1999) while ALM is equipotent through both routes of administration. Analysis of the sleep/wake data confirmed the equipotent effects of both drugs through both routes of administration at the concentrations tested.

\section{WATER MAZE}

All water maze (WM) tasks occurred in a pool $68^{\prime \prime}$ in diameter and $25^{\prime \prime}$ in depth, containing water at $24 \pm 2{ }^{\circ} \mathrm{C}$ made opaque by the addition of non-toxic, water soluble black paint and milk powder. Since all tests took place during the dark period, distinctive spatial cues were made of small "rice" lights colored blue, yellow, and green. Patterns of lights in distinct shapes (circle, square, diamond, " $\mathrm{T}$ " shape) were clearly visible from within the pool. Preliminary studies determined the minimum number of lights that were needed for learning to occur. A $10 \mathrm{~cm}$ diameter platform was submerged approximately $1 \mathrm{~cm}$ below the surface of the water in one of 6 locations (Figure 1). The platform location determined the orientation of the 4 quadrants used for analysis. Both WM tasks were similar to previous reports (Wenk, 2004; Ward et al., 2009).

\section{TEST OF SPATIAL REFERENCE MEMORY}

The acquisition phase occurred in one session consisting of 12-15 consecutive trials with a $60 \mathrm{~s}$ inter-trial interval. For each trial, 


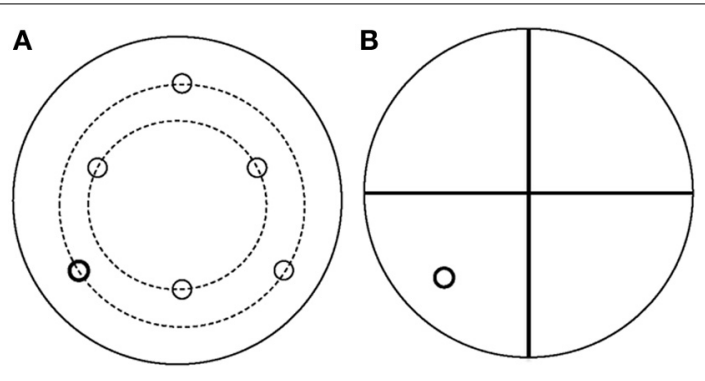

FIGURE 1 | Schematic of the water maze apparatus used for both spatial reference and spatial working memory tasks. (A) Schematic of the platform locations. (B) Example of quadrant orientations used for analysis used for the platform indicated in bold. Quadrant locations were always oriented so that the platform was central within a quadrant.

rats were placed in the WM facing the wall in one of three quadrants that did not contain the hidden platform. The location of the hidden platform remained constant across all trials. Rats were given $60 \mathrm{~s}$ to locate the platform. If the rats did not locate the platform within this period, they were guided to the platform location. When the rats reached the platform, they were allowed to remain on the platform for approximately $15 \mathrm{~s}$ before being placed in a dry holding cage for the next $60 \mathrm{~s}$. This training sequence continued until the rats learned the task, typically 12-15 trials.

On the following day, rats were dosed with ALM, ZOL or $\mathrm{VEH}$ at ZT18 and a retention probe trial was performed $90 \mathrm{~min}$ later in which the rats were returned to the WM but the platform had been removed. A total of 40 rats were subjected to SD for $6 \mathrm{~h}$ prior to drug administration, and 42 were left undisturbed during this period (Table 1). Rats were started in the quadrant opposite the target quadrant and allowed to swim for $30 \mathrm{~s}$. All trials were recorded by video camera and analyzed with Ethovision XT software (Noldus, Leesburg, VA). Test measures for the retention probe were time spent in target quadrant, latency to target quadrant, frequency of entrance into target quadrant, and total distance traveled. Swim speed was calculated to control for nonspecific effects.

\section{TEST OF SPATIAL WORKING MEMORY}

The SWM task consisted of 6 pairs of trials, one for each platform location (Figure 1A). In the first trial, a cued platform marked with a flag was placed in one of 6 positions in the WM. Rats were released facing the wall from one of the 3 quadrants not containing the platform and were allowed $120 \mathrm{~s}$ to locate the cued platform before the researcher guided the rats to the platform. This procedure provided all rats the opportunity to learn the platform location even if they did not find it on their own. After $15 \mathrm{~s}$ on the platform, the rats were removed from the WM and placed in a holding cage. The flag was then removed but the platform remained in the same location as in the first trial. Following a delay of 1,5 , or $10 \mathrm{~min}$ in the holding cage, the rats were placed back in the WM into one of the 2 quadrants that did not contain the platform and was not the starting quadrant during the first trial. Once the rats found the platform, they were removed after approximately $5 \mathrm{~s}$ and placed back in a holding cage for $10 \mathrm{~min}$ before a new pair of trials with a novel platform location was given. The order of delays was counterbalanced so that each rat was tested twice at 1, 5, or 10 min delays between the cued and hidden platforms. All trials were recorded by video camera and analyzed with Ethovision XT software (Noldus, Leesburg, VA). Test measures were time to locate the platform and the swim velocity during all tests.

\section{STATISTICAL ANALYSIS}

Statistical analyses were performed using SigmaPlot 12.3 (Systat Software Inc., San Jose, CA). Sleep/wake data (W, NREM, and REM time) were analyzed in $30 \mathrm{~min}$ bins and compared between drug groups using Two-Way mixed-model ANOVA on factors "drug group" (between subjects) and "time" (within subjects). SRM performance parameters (latency, duration and frequency in target quadrant, total distance traveled) were analyzed using a One-Way ANOVA. SWM performance measures (velocity, time to platform, percent found) by delay time were analyzed using Two-Way mixed-model ANOVA on factors "drug group" (between subjects) and "time" (within subjects). Significance levels were set at $\alpha=0.05$. When ANOVA indicated significance, Bonferroni $t$-tests were used for post hoc analyses.

\section{RESULTS}

Drug concentrations were chosen to be equipotent at sleep promotion based on our previous experience (Morairty et al., 2012). Although ZOL produced a more rapid onset to sleep under both $\mathrm{SD}$ and undisturbed conditions (No SD: $\mathrm{ZOL}=6.6 \mathrm{~min}, \mathrm{VEH}=$ $32.2 \mathrm{~min}, \mathrm{ALM}=25.4 \mathrm{~min} ; \mathrm{SD}: \mathrm{ZOL}=5.9 \mathrm{~min}, \mathrm{VEH}=20.0 \mathrm{~min}$, $\mathrm{ALM}=15.5 \mathrm{~min}), \mathrm{ALM}$ - and ZOL-treated rats slept equivalent amounts during the last hour before the WM test (Figure 2; No $\mathrm{SD}: \mathrm{ZOL}=69.4 \%, \mathrm{ALM}=62.3 \%, \mathrm{VEH}=37.6 \%$; $\mathrm{SD}: \mathrm{ZOL}=$ $69.6 \%, \mathrm{ALM}=71.5 \%, \mathrm{VEH}=52.0 \%)$.

\section{TEST OF SPATIAL REFERENCE MEMORY}

For all performance measures analyzed, rats treated with ZOL showed significant impairments while ALM- and VEH-treated rats were indistinguishable (Figure 3). Following ZOL, the latency to the target zone increased (No SD: $\mathrm{ZOL}=14.1 \mathrm{~s}, \mathrm{VEH}=5.7 \mathrm{~s}$, $\mathrm{ALM}=5.8 \mathrm{~s} ; \mathrm{SD}: \mathrm{ZOL}=18.4 \mathrm{~s}, \mathrm{VEH}=4.2 \mathrm{~s}, \mathrm{ALM}=3.6 \mathrm{~s})$ and the duration in the target zone (No SD: $\mathrm{ZOL}=5.5 \mathrm{~s}, \mathrm{VEH}=$ $8.4 \mathrm{~s}, \mathrm{ALM}=7.9 \mathrm{~s} ; \mathrm{SD}: \mathrm{ZOL}=4.8 \mathrm{~s}, \mathrm{VEH}=7.7 \mathrm{~s}, \mathrm{ALM}=7.8 \mathrm{~s})$, frequency entering the target zone (No SD: $\mathrm{ZOL}=1.2, \mathrm{VEH}=$ $2.7, \mathrm{ALM}=2.5 ; \mathrm{SD}: \mathrm{ZOL}=0.9, \mathrm{VEH}=2.8, \mathrm{ALM}=2.9)$ and the distance traveled (No SD: $Z O L=472 \mathrm{~cm}, \mathrm{VEH}=666 \mathrm{~cm}$, $\mathrm{ALM}=725 \mathrm{~cm}$; SD: $\mathrm{ZOL}=343 \mathrm{~cm}, \mathrm{VEH}=709 \mathrm{~cm}, \mathrm{ALM}=$ $775 \mathrm{~cm}$ ) all decreased compared to VEH and ALM-treated rats. ALM-treated rats did not differ from VEH-treated rats on any of these four measures. Performance in the SRM task was not significantly affected by $6 \mathrm{~h} \mathrm{SD}$ for any measure within any group.

Swim patterns in the WM were different for ZOL-treated rats compared to VEH- and ALM-treated rats (Figure 4). Both VEH and ALM rats repeatedly swam across the WM and typically swam through the area where the hidden platform was present on the previous day (Figure 4A). In contrast, ZOL-treated rats primarily swam around the perimeter of the WM, a pattern typical of a rat during its first exposure to the WM. 

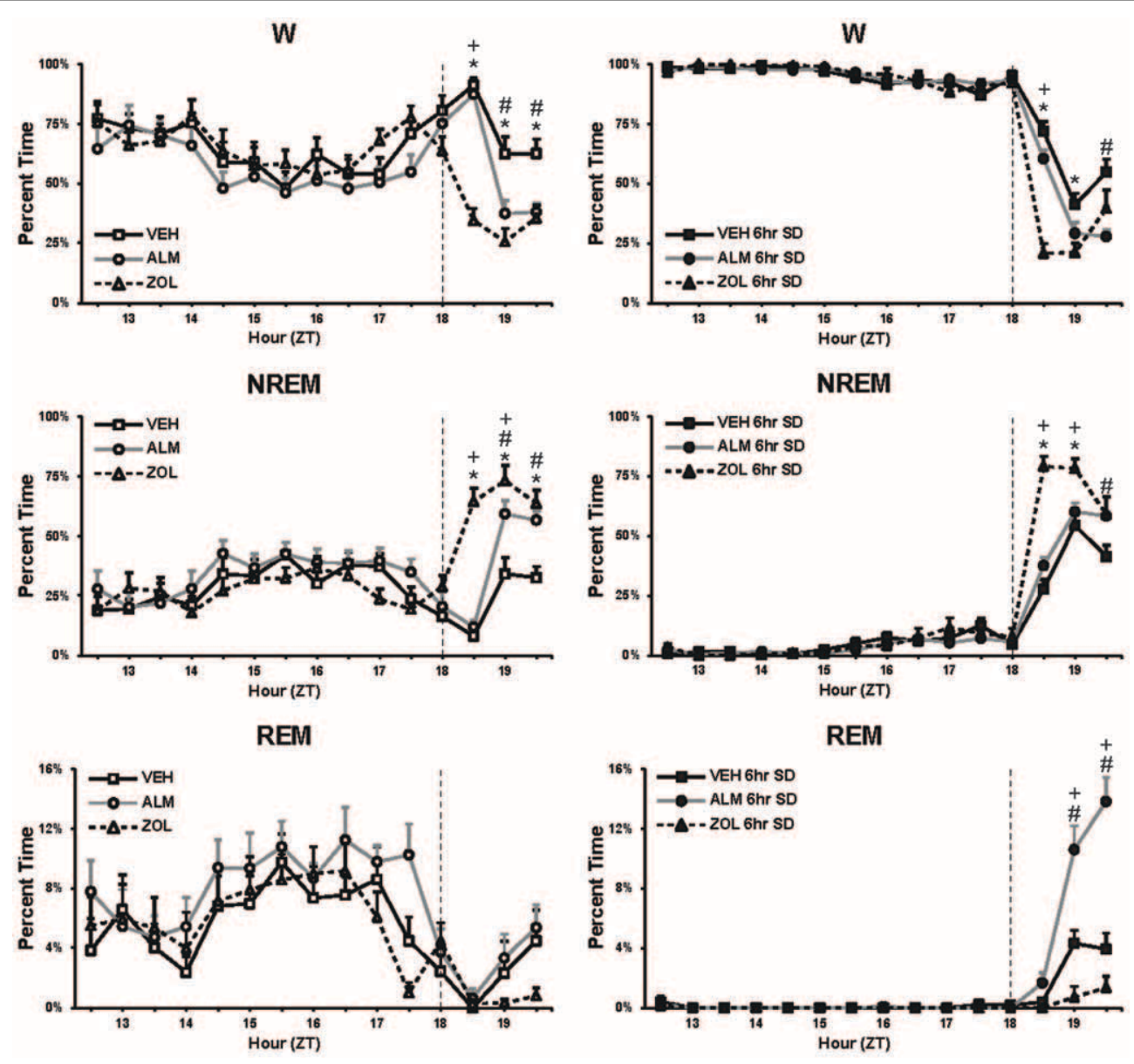

FIGURE 2 | Percent time spent in W, NREM, and REM during baseline (left panels) and during $6 \mathrm{~h}$ SD (right panels). The vertical line in each panel at ZT18 depicts the time of drug administration. At the end of the recording time displayed in these panels, rats were

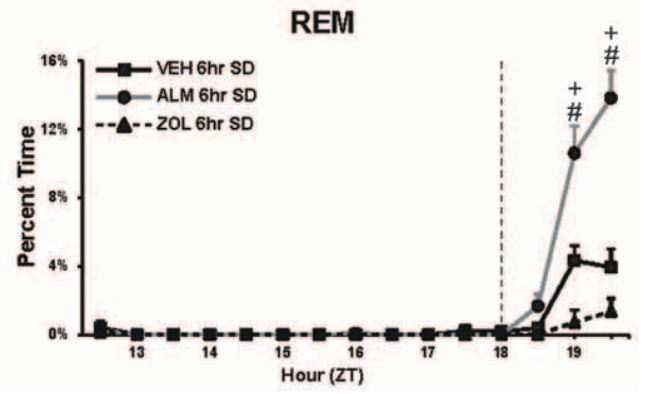

tested in the water maze. Note that, for the 60 min prior to testing (ZT19.5), the ALM and ZOL groups slept similar amounts. *, ZOL different from $V E H ;+, Z O L$ different ALM; \#, ALM different from VEH; $p<0.05$.

\section{TEST OF SPATIAL WORKING MEMORY}

ZOL-treated rats performed poorly in the SWM task compared to either VEH- or ALM-treated rats (Figures 5, 6). ZOL-treated rats took longer to find the platform (No SD: ZOL $=43.4-47.3 \mathrm{~s}$, $\mathrm{VEH}=20.6-30.0 \mathrm{~s}$, ALM $=22.5-30.7 \mathrm{~s} ; \mathrm{SD}: \mathrm{ZOL}=48.0$ $55.5 \mathrm{~s}, \mathrm{VEH}=26.9-31.0 \mathrm{~s}, \mathrm{ALM}=25.6-28.2 \mathrm{~s})$ and swam more slowly (No SD: ZOL $=14.0-14.2 \mathrm{~cm} / \mathrm{s}, \mathrm{VEH}=18.0-19.6 \mathrm{~cm} / \mathrm{s}$, $\mathrm{ALM}=18.9-20.4 \mathrm{~cm} / \mathrm{s} ; \mathrm{SD}: \mathrm{ZOL}=9.9-10.9 \mathrm{~cm} / \mathrm{s}, \mathrm{VEH}=15.7-$ $16.8 \mathrm{~cm} / \mathrm{s}, \mathrm{ALM}=17.5-18.1 \mathrm{~cm} / \mathrm{s}$ ) than the $\mathrm{VEH}$ or ALM rats (Figure 5). These measures were not affected by increasing the delay from 1 to $5 \mathrm{~min}$ or $10 \mathrm{~min}$ for any of the 6 groups of rats.

The goal for the SWM task was to locate the platform. VEHand ALM-treated rats found the platform the majority of the time in both SD and undisturbed conditions $(83.3-100 \%$ for $\mathrm{VEH}$ and 79.2-87.5\% for ALM; Figure 6). Conversely, ZOL-treated rats failed to find the platform most of the time $(22.7-50.0 \%$ success rate). Interestingly, ZOL-treated rats also often failed to find the cued platform during the training phase of each pair of trials (Figure 7). The ZOL-treated rats in the baseline group found the cued platform $54.4 \%$ of the time while the SD ZOL-treated group were successful $53.8 \%$ of the time as compared to $98.6 \%$ for ALM-treated rats in the baseline group and 100\% following $\mathrm{SD}$ and $100 \%$ of the time for all $\mathrm{VEH}$-treated rats. A trend toward improved performance was observed with progressive trials in the ZOL-treated rats.

\section{DISCUSSION}

Though differing in the latency to induce sleep at the doses tested, ALM, and ZOL were equally effective at promoting sleep during the $90 \mathrm{~min}$ period prior to performance testing and both compounds significantly increased sleep compared to VEH. ALMtreated rats were indistinguishable from VEH-treated rats in their performance of both the SRM and SWM tasks. In contrast, ZOL caused significant impairments in both tasks. Specifically, in the SRM task, ZOL increased the latency to, the duration in, and the frequency of entering the target zone. In the SWM task, ZOL increased the time to find the platform, decreased the swim velocity and decreased the success rate in finding the platform. These results support the hypothesis that dual Hcrt receptor antagonism 

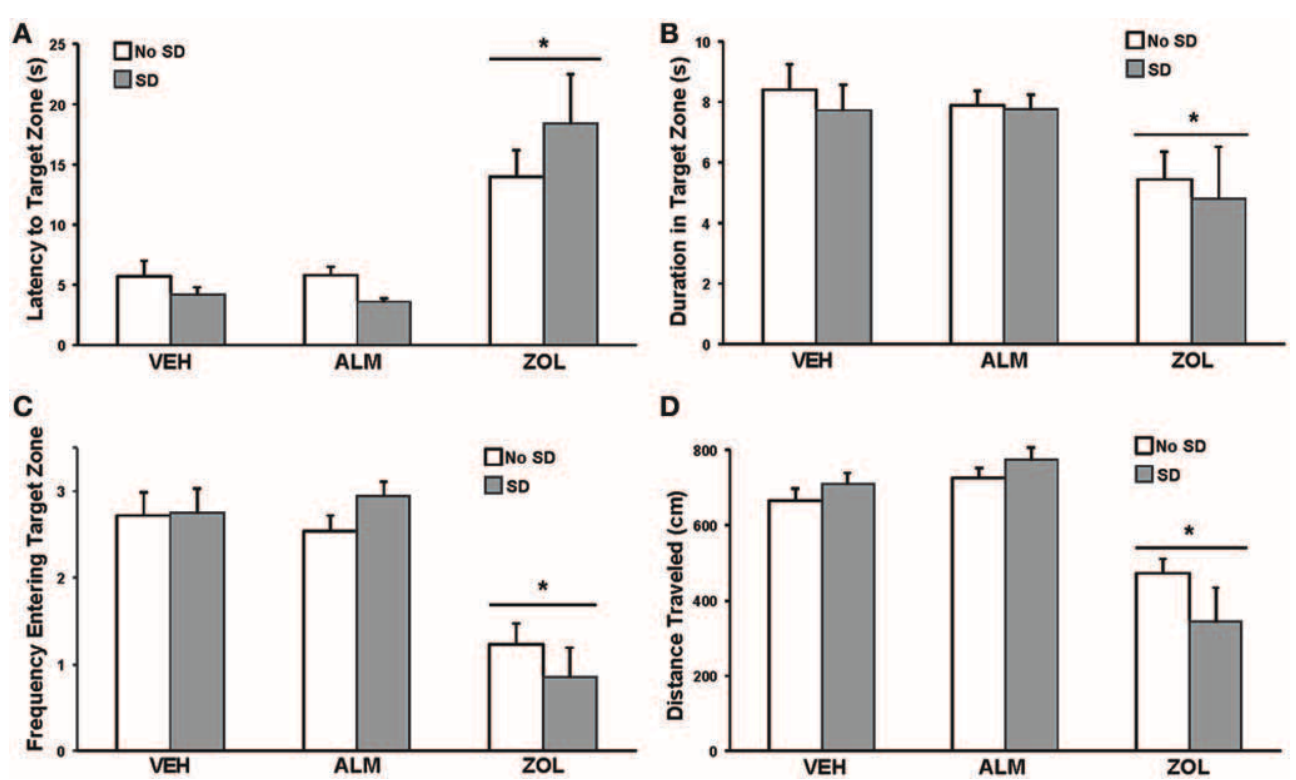

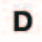

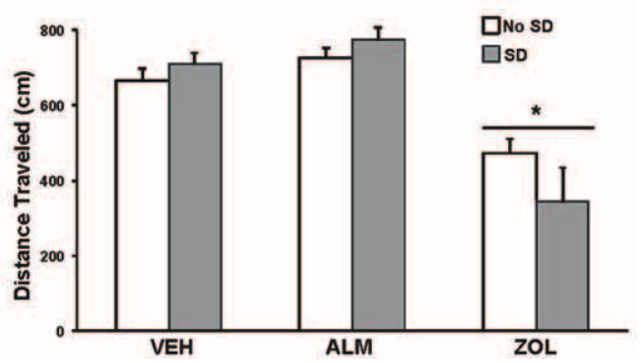

FIGURE 3 | Measures of performance in the spatial reference memory task. For all measures, ZOL-treated rats performed poorly compared to $\mathrm{VEH}$ - and ALM-treated rats. For all measures, the ALM-treated rats were indistinguishable from the VEH-treated rats.

(A) Latency to the target zone. (B) Duration in the target zone. (C) Frequency entering the target zone. (D) Total distance traveled. For all measures, ANOVA revealed an effect of drug condition without an effect of SD. ${ }^{*}, p<0.05$.

A VEH

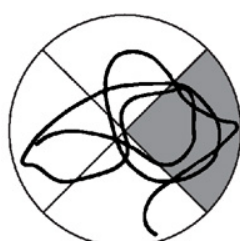

B

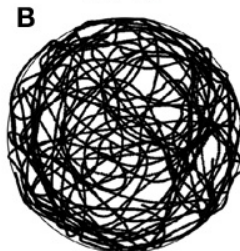

C

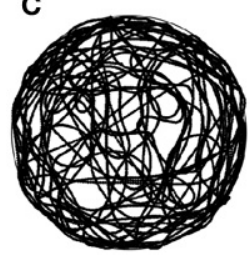

ALM
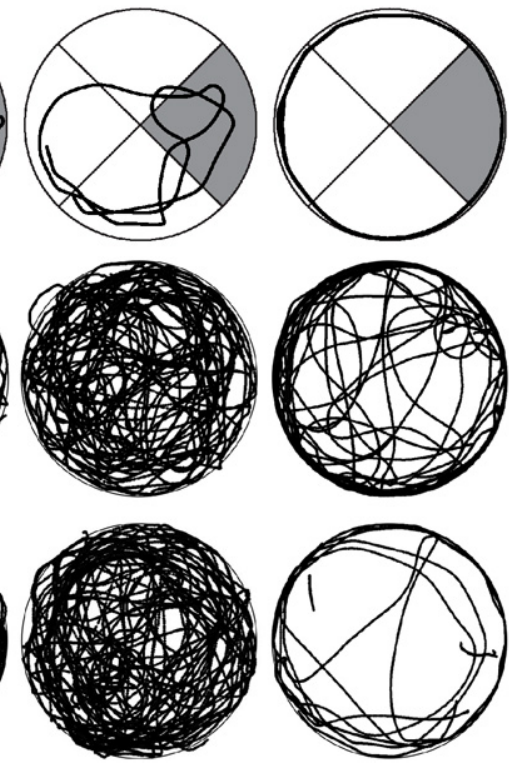

FIGURE 4 | Swim patterns during the spatial reference memory probe trials following VEH (left columns), ALM (center columns) and ZOL (right columns). (A) Examples of individual rats. The target quadrant is highlighted in gray. (B) Traces for all rats in the undisturbed condition. (C) Traces for all rats in the $6 \mathrm{~h}$ SD condition. Note that the searching pattern for $\mathrm{VEH}$ and ALM are similar while the pattern following ZOL remains primarily around the perimeter of the maze.

effectively promotes sleep without the functional impairments observed following $\mathrm{GABA}_{\mathrm{A}}$ receptor modulation.

An alternative explanation of the results obtained is that $\mathrm{ZOL}$ treated rats were not motivated to perform the tasks rather than having memory/cognitive deficits. ZOL-treated rats had decreased distance traveled during the SRM task and decreased velocity during the SWM task, which could indicate a lack of motivation to escape the WM. Further, the lower success rate in finding the cued platform during the training trials for the SWM task could be interpreted as an absence of motivation to escape. However, ZOL rats did not simply float in the WM; they swam continuously, primarily circling the perimeter of the WM. As mentioned above, this swim pattern is typical of an untrained rat during its first exposure to the WM. Although not measured in this study, it is possible that the decreased distance traveled during the SRM task and decreased velocity during the SWM task are due to motor deficits produced by ZOL. This hypothesis is supported by previous studies that found prominent motor effects following ZOL administration (Depoortere et al., 1986; Steiner et al., 2011; Milic et al., 2012).

The SD protocol in these studies was included to assess whether moderate increases in sleep drive would exacerbate any cognitive deficits found following ALM or ZOL administration and also produce deficits in VEH-treated rats. While the primary active period of nocturnal rodents such as the rat is during the dark phase, rats still sleep approximately $30 \%$ of the time during this period and increasing wake duration during the dark period should create a mild sleep deficit (see Figure 2). Therefore, a portion of our experimental protocol involved SD during the $6 \mathrm{~h}$ of the dark period just prior to drug administration at ZT18. 

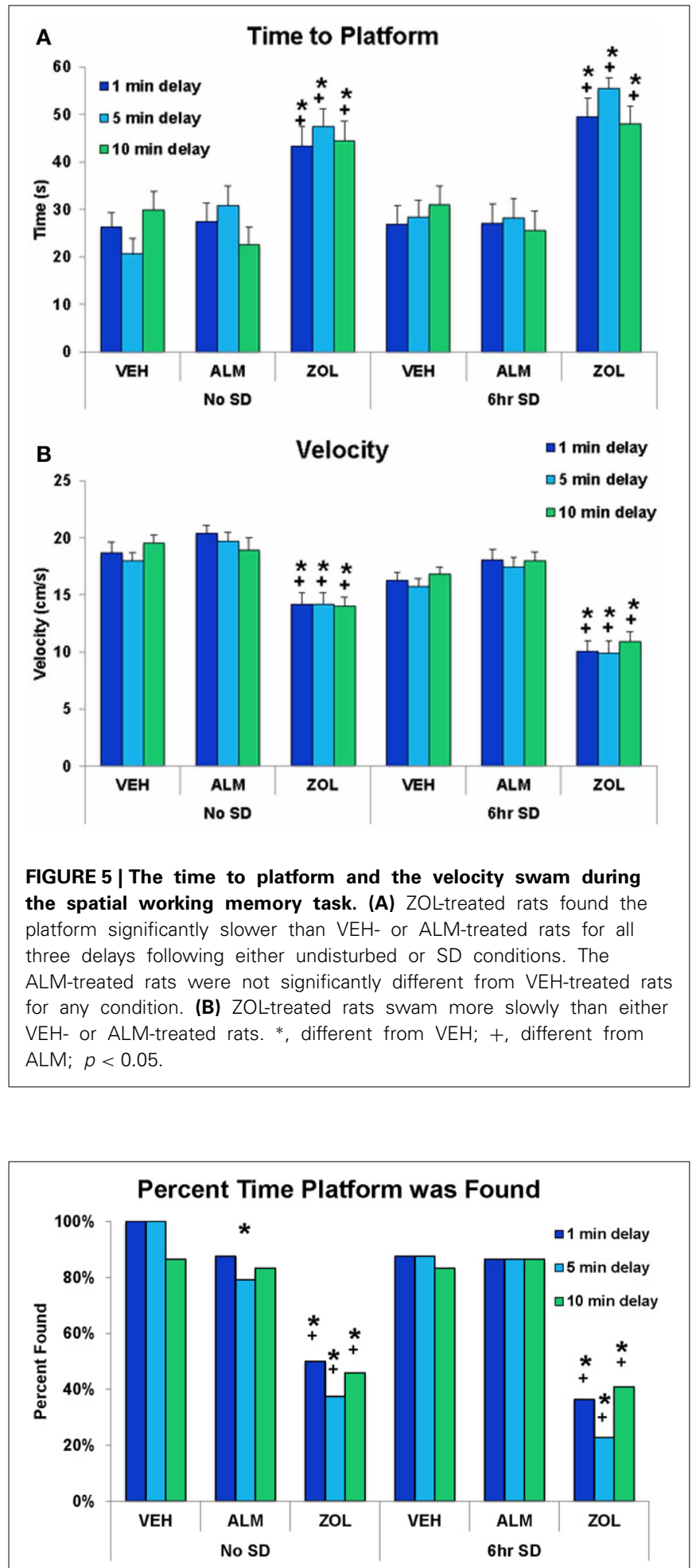

FIGURE 6 | Success rate in locating the platform during the test trials in the spatial working memory task. ZOL-treated rats found the platform significantly fewer times compared to $\mathrm{VEH}$ - or ALM-treated rats for all three delays and following both the undisturbed and SD conditions. In each trial, an individual rat either found or didn't find the platform; thus, there is no variation to represent as error bars in the graphs. ${ }^{*}$, different from $\mathrm{VEH} ;+$, different from ALM; $p<0.05$.
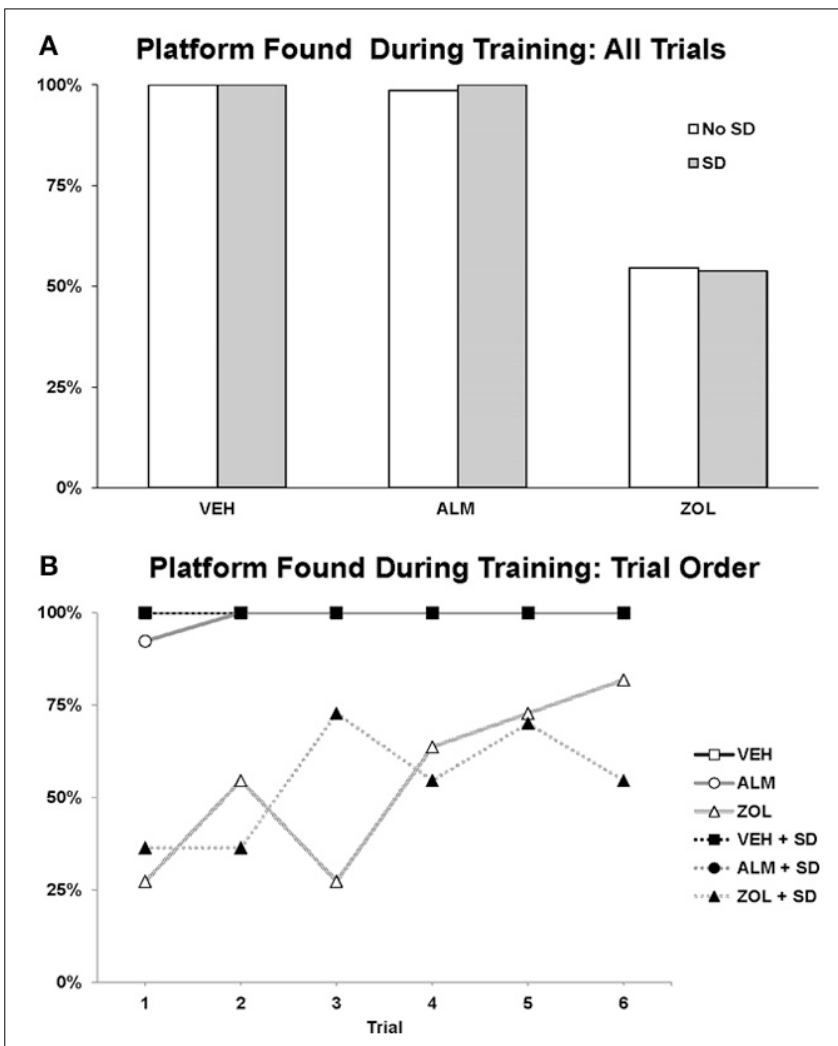

FIGURE 7 | Success rate in locating the platform during the training trials in the spatial working memory task. The platform was cued during these training trials by a flag. (A) The percentage of times the platform was found across all 6 training trials. (B) The percentage of times the platform was found trial by trial. Note that the ZOL rats tended to progressively improve across trials. In each trial, an individual rat either found or didn't find the platform; thus, there is no variation to represent as error bars in the graphs.

Although we did not find significant effects of SD vs. non-SD within any of the 3 dosing conditions, these results are likely due to the fact that we allowed the rats to sleep after drug administration until water maze testing began. This undisturbed period lasted only 60-90 min but provided an opportunity for the experimental subjects to recover from this mild sleep deprivation. If the SD were continued until testing, increased memory deficits might have been observed. Further studies are needed to determine whether this is indeed to case.

ZOL is a widely prescribed hypnotic medication that can be well-tolerated when taken as directed (Greenblatt and Roth, 2012). However, numerous adverse effects associated with ZOL usage have been reported including driving impairment (Verster et al., 2006; Gunja, 2013), effects on balance and postural tone (Zammit et al., 2008), interference with memory consolidation (Balkin et al., 1992; Wesensten et al., 1996, 2005; Mintzer and Griffiths, 1999; Morgan et al., 2010) and increased incidence of complex behaviors during sleep (Hoever et al., 2010). Some studies investigated the effects of daytime administration of $\mathrm{ZOL}$ and tested psychomotor function upon arousal from naps (Wesensten et al., 2005; Storm et al., 2007), a protocol which our experiments closely mimic. In these studies, ZOL or melatonin was 
administered at either 10:00 or 13:00. Following a 1.5-2 h nap opportunity, subjects were awakened and required to perform a series of psychomotor and cognitive tests. Significant performance decrements were observed following ZOL in cognitive, vigilance and memory tasks while little to no decrements were found following melatonin. The results of $\mathrm{ZOL}$ administration on rat cognitive performance in the current study correlate well with these deficits found in humans.

In contrast, the high level of performance following ALM in both of our memory tasks suggests a high degree of safety at concentrations with hypnotic efficacy. Indeed, a recent study found no performance decrements in a variant of the WM SRM task at three-fold the concentration of ALM that we used (Dietrich and Jenck, 2010). Furthermore, another recent study found no effect of ALM at $300 \mathrm{mg} / \mathrm{kg}$ on motor function (Steiner et al., 2011). In humans, however, psychometric test battery assessment of the effect of ALM administered in the daytime found reductions in vigilance, alertness, and visuomotor and motor coordination at dose concentrations of 400-1000 mg (Hoever et al., 2010, 2012a). Notably, $400 \mathrm{mg}$ ALM is within the therapeutic dose range required to improve sleep in patients with primary insomnia (Hoever et al., 2012b). Therefore, performance deficits following ALM occur within the range of hypnotic efficacy in humans. In one report, pharmacokinetic/pharmacodynamic modeling suggests that doses of $500 \mathrm{mg}$ ALM and $10 \mathrm{mg}$ ZOL are equivalent with respect to subjectively assessed alertness (Hoever et al., 2010). Since we find hypnotic efficacy to be achieved at roughly similar dose concentrations, there may be species differences in pharmacokinetic/pharmacodynamics of ALM and/or ZOL. While not uncommon, this makes direct translational interpretations of the present data more difficult. Regardless, in both rodents and humans, ALM appears to have a significantly better safety profile than ZOL with regards to cognitive/memory domains.

\section{CONCLUSION}

ALM and ZOL are effective hypnotics in multiple mammalian species (Brisbare-Roch et al., 2007; Hoever et al., 2010, 2012a,b; Morairty et al., 2012). They act through entirely different mechanisms of action, and their effects on cognition, psychomotor vigilance and memory are in stark contrast to one another. We found that at equipotent hypnotic concentrations, ZOL impaired SRM and SWM but ALM did not. These results support the hypothesis that antagonism of the Hcrt system can provide hypnotic efficacy without the impairments found by inducing sleep through $\mathrm{GABA}_{\mathrm{A}}$ modulation.

\section{ACKNOWLEDGMENTS}

We thank Sarah Black, Jacqueline DeRose, Sinom Fisher, Gregory Parks, Michael Schwartz, Alexia Thomas and Rhiannan Williams for feedback on the manuscript. Supported by USAMRMC grant W81XWH-09-2-0081.

\section{REFERENCES}

Balkin, T. J., O’Donnell, V. M., Wesensten, N., McCann, U., and Belenky, G. (1992). Comparison of the daytime sleep and performance effects of zolpidem versus triazolam. Psychopharmacology 107, 83-88. doi: 10.1007/BF02244970
Belenky, G., Wesensten, N. J., Thorne, D. R., Thomas, M. L., Sing, H. C., Redmond, D. P., et al. (2003). Patterns of performance degradation and restoration during sleep restriction and subsequent recovery: a sleep dose-response study. J. Sleep Res. 12, 1-12. doi: 10.1046/j.1365-2869.2003. 00337.x

Betschart, C., Hintermann, S., Behnke, D., Cotesta, S., Fendt, M., Gee, C. E., et al. (2013). Identification of a novel series of orexin receptor antagonists with a distinct effect on sleep architecture for the treatment of insomnia. J. Med. Chem. 56, 7590-7607. doi: 10.1021/jm4007627

Brisbare-Roch, C., Dingemanse, J., Koberstein, R., Hoever, P., Aissaoui, H., Flores, S., et al. (2007). Promotion of sleep by targeting the orexin system in rats, dogs and humans. Nat. Med. 13, 150-155. doi: 10.1038/nm1544

Coleman, P. J., Schreier, J. D., Cox, C. D., Breslin, M. J., Whitman, D. B., Bogusky, M. J., et al. (2012). Discovery of $[(2 R, 5 R)-5-\{[(5-f l u o r o$ pyridin-2-yl)oxy]methyl\}-2-methylpiperidin-1-yl][5-methyl-2 -(pyrimidin-2yl)phenyl]methanone (MK-6096): a dual orexin receptor antagonist with potent sleep-promoting properties. ChemMedChem 7, 415-424, 337. doi: $10.1002 / \mathrm{cmdc} .201200025$

de Lecea, L. (2012). Hypocretins and the neurobiology of sleep-wake mechanisms. Prog. Brain Res. 198, 15-24. doi: 10.1016/B978-0-444-59489-1.00003-3

Depoortere, H., Zivkovic, B., Lloyd, K. G., Sanger, D. J., Perrault, G., Langer, S. Z., and Bartholini, G. (1986). Zolpidem, a novel nonbenzodiazepine hypnotic. I. Neuropharmacological and behavioral effects. J. Pharmacol. Exp. Ther. 237, 649-658.

Dietrich, H., and Jenck, F. (2010). Intact learning and memory in rats following treatment with the dual orexin receptor antagonist almorexant. Psychopharmacology 212, 145-154. doi: 10.1007/s00213-010-1933-5

Dolder, C. R., and Nelson, M. H. (2008). Hypnosedative-induced complex behaviours: incidence, mechanisms and management. CNS Drugs 22, 1021-1036. doi: 10.2165/0023210-200822120-00005

Dugovic, C., Shelton, J. E., Aluisio, L. E., Fraser, I. C., Jiang, X., Sutton, S. W., et al. (2009). Blockade of orexin-1 receptors attenuates orexin-2 receptor antagonism-induced sleep promotion in the rat. J. Pharmacol. Exp. Ther. 330, 142-151. doi: 10.1124/jpet.109.152009

Greenblatt, D. J., and Roth, T. (2012). Zolpidem for insomnia. Expert Opin. Pharmacother. 13, 879-893. doi: 10.1517/14656566.2012.667074

Gunja, N. (2013). In the Zzz zone: the effects of z-drugs on human performance and driving. J. Med. Toxicol. 9, 163-171. doi: 10.1007/s13181-013-0294-y

Herring, W. J., Snyder, E., Budd, K., Hutzelmann, J., Snavely, D., Liu, K., et al. (2012). Orexin receptor antagonism for treatment of insomnia: a randomized clinical trial of suvorexant. Neurology 79, 2265-2274. doi: 10.1212/WNL.0b013e31827688ee

Hoever, P., de Haas, S., Winkler, J., Schoemaker, R. C., Chiossi, E., van Gerven, J., and Dingemanse, J. (2010). Orexin receptor antagonism, a new sleep-promoting paradigm: an ascending single-dose study with almorexant. Clin. Pharmacol. Ther. 87, 593-600. doi: 10.1038/clpt.2010.19

Hoever, P., de Haas, S. L., Dorffner, G., Chiossi, E., van Gerven, J. M., and Dingemanse, J. (2012a). Orexin receptor antagonism: an ascending multiple-dose study with almorexant. J. Psychopharmacol. 26, 1071-1080. doi: $10.1177 / 0269881112448946$

Hoever, P., Dorffner, G., Benes, H., Penzel, T., Danker-Hopfe, H., Barbanoj, M. J., et al. (2012b). Orexin receptor antagonism, a new sleep-enabling paradigm: a proof-of-concept clinical trial. Clin. Pharmacol. Ther. 91, 975-985. doi: 10.1038/clpt.2011.370

Huang, M. P., Radadia, K., Macone, B. W., Auerbach, S. H., and Datta, S. (2010). Effects of eszopiclone and zolpidem on sleep-wake behavior, anxietylike behavior and contextual memory in rats. Behav. Brain Res. 210, 54-66. doi: 10.1016/j.bbr.2010.02.018

Inutsuka, A., and Yamanaka, A. (2013). The regulation of sleep and wakefulness by the hypothalamic neuropeptide orexin/hypocretin. Nagoya J. Med. Sci. 75, 29-36.

Lamond, N., Jay, S. M., Dorrian, J., Ferguson, S. A., Jones, C., and Dawson, D. (2007). The dynamics of neurobehavioural recovery following sleep loss. J. Sleep Res. 16, 33-41. doi: 10.1111/j.1365-2869.2007.00574.x

Mai, E., and Buysse, D. J. (2008). Insomnia: prevalence, impact, pathogenesis, differential diagnosis, and evaluation. Sleep Med. Clin. 3, 167-174. doi: 10.1016/j.jsmc.2008.02.001

Makaron, L., Moran, C. A., Namjoshi, O., Rallapalli, S., Cook, J. M., and Rowlett, J. K. (2013). Cognition-impairing effects of benzodiazepine-type drugs: role of 
GABAA receptor subtypes in an executive function task in rhesus monkeys. Pharmacol. Biochem. Behav. 104, 62-68. doi: 10.1016/j.pbb.2012.12.018

Marcus, J. N., Aschkenasi, C. J., Lee, C. E., Chemelli, R. M., Saper, C. B., Yanagisawa, M., et al. (2001). Differential expression of orexin receptors 1 and 2 in the rat brain. J. Comp. Neurol. 435, 6-25. doi: 10.1002/cne.1190

Mattila, M. J., Vanakoski, J., Kalska, H., and Seppala, T. (1998). Effects of alcohol, zolpidem, and some other sedatives and hypnotics on human performance and memory. Pharmacol. Biochem. Behav. 59, 917-923. doi: 10.1016/S00913057(97)00506-6

Mieda, M., and Sakurai, T. (2013). Orexin (hypocretin) receptor agonists and antagonists for treatment of sleep disorders. Rationale for development and current status. CNS Drugs 27, 83-90. doi: 10.1007/s40263-012-0036-8

Milic, M., Divljakovic, J., Rallapalli, S., van Linn, M. L., Timic, T., Cook, J. M., et al. (2012). The role of alphal and alpha5 subunit-containing GABAA receptors in motor impairment induced by benzodiazepines in rats. Behav. Pharmacol. 23, 191-197. doi: 10.1097/FBP.0b013e3283512c85

Mintzer, M. Z., and Griffiths, R. R. (1999). Selective effects of zolpidem on human memory functions. J. Psychopharmacol. 13, 18-131. doi: $10.1177 / 026988119901300103$

Morairty, S. R., Hedley, L., Flores, J., Martin, R., and Kilduff, T. S. (2008). Selective 5HT2A and 5HT6 receptor antagonists promote sleep in rats. Sleep 31, 34-44.

Morairty, S. R., Revel, F. G., Malherbe, P., Moreau, J. L., Valladao, D., Wettstein, J. G., et al. (2012). Dual hypocretin receptor antagonism is more effective for sleep promotion than antagonism of either receptor alone. PLoS ONE 7:e39131. doi: 10.1371/journal.pone.0039131

Morgan, P. T., Kehne, J. H., Sprenger, K. J. and Malison, R. T. (2010). Retrograde effects of triazolam and zolpidem on sleep-dependent motor learning in humans. J. Sleep Res. 19, 157-164. doi: 10.1111/j.1365-2869.2009.00757.x

NIH. (2005). National Institutes of Health State of the Science Conference statement on Manifestations and Management of Chronic Insomnia in Adults. Sleep $28,1049-57$.

Otmani, S., Demazieres, A., Staner, C., Jacob, N., Nir, T., Zisapel, N., et al. (2008). Effects of prolonged-release melatonin, zolpidem, and their combination on psychomotor functions, memory recall, and driving skills in healthy middle aged and elderly volunteers. Hum. Psychopharmacol. 23, 693-705. doi: 10.1002/hup. 980

Peyron, C., Tighe, D. K., van den Pol, A. N., de Lecea, L., Heller, H. C., Sutcliffe, J. G., et al. (1998). Neurons containing hypocretin (orexin) project to multiple neuronal systems. J. Neurosci. 18, 9996-10015.

Revel, F. G., Moreau, J. L., Gainetdinov, R. R., Ferragud, A., Velazquez-Sanchez, C., Sotnikova, T. D., et al. (2012). Trace amine-associated receptor 1 partial agonism reveals novel paradigm for neuropsychiatric therapeutics. Biol. Psychiatry 72, 934-942. doi: 10.1016/j.biopsych.2012.05.014

Revel, F. G., Moreau, J. L., Pouzet, B., Mory, R., Bradaia, A., Buchy, D., et al. (2013). A new perspective for schizophrenia: TAAR1 agonists reveal antipsychotic- and antidepressant-like activity, improve cognition and control body weight. Mol. Psychiatry 18, 543-556. doi: 10.1038/mp.2012.57

Roth, T. (2007). Insomnia: definition, prevalence, etiology, and consequences. J. Clin. Sleep Med. 3, S7-S10.

Saper, C. B. (2013). The neurobiology of sleep. Continuum (Minneap Minn) 19, 19-31. doi: 10.1212/01.CON.0000427215.07715.73

Soto, P. L., Ator, N. A., Rallapalli, S. K., Biawat, P., Clayton, T., Cook, J. M., et al. (2013). Allosteric modulation of GABAA receptor subtypes: effects on visual recognition and visuospatial working memory in rhesus monkeys. Neuropsychopharmacology 38, 2315-2325. doi: 10.1038/npp.2013.137

Steiner, M. A., Lecourt, H., Strasser, D. S., Brisbare-Roch, C. and Jenck, F. (2011). Differential effects of the dual orexin receptor antagonist almorexant and the GABA(A)-alphal receptor modulator zolpidem, alone or combined with ethanol, on motor performance in the rat. Neuropsychopharmacology 36, 848-856. doi: 10.1038/npp.2010.224

Storm, W. F., Eddy, D. R., Welch, C. B., Hickey, P. A., Fischer, J., and Cardenas, R. (2007). Cognitive performance following premature awakening from zolpidem or melatonin induced daytime sleep. Aviat. Space Environ. Med. 78, 10-20.

Uslaner, J. M., Tye, S. J., Eddins, D. M., Wang, X., Fox, S. V., Savitz, A. T., et al. (2013). Orexin receptor antagonists differ from standard sleep drugs by promoting sleep at doses that do not disrupt cognition. Sci. Transl. Med. 5, 179ra44. doi: 10.1126/scitranslmed.3005213

Vanover, K. E., Edgar, D. M., Seidel, W. F., Hogenkamp, D. J., Fick, D. B., Lan, N. C., et al. (1999). Response-rate suppression in operant paradigm as predictor of soporific potency in rats and identification of three novel sedative-hypnotic neuroactive steroids. J. Pharmacol. Exp. Ther. 291, 1317-1323.

Verster, J. C., Veldhuijzen, D. S., Patat, A., Olivier, B., and Volkerts, E. R. (2006). Hypnotics and driving safety: meta-analyses of randomized controlled trials applying the on-the-road driving test. Curr. Drug Saf. 1, 63-71. doi: $10.2174 / 157488606775252674$

Verster, J. C., Volkerts, E. R., Schreuder, A. H., Eijken, E. J., van Heuckelum, J. H., Veldhuijzen, D. S., et al. (2002). Residual effects of middle-of-the-night administration of zaleplon and zolpidem on driving ability, memory functions, and psychomotor performance. J. Clin. Psychopharmacol. 22, 576-583. doi: 10.1097/00004714-200212000-00007

Ward, C. P., McCarley, R. W., and Strecker, R. E. (2009). Experimental sleep fragmentation impairs spatial reference but not working memory in Fischer/Brown Norway rats. J. Sleep Res. 18, 238-244. doi: 10.1111/j.1365-2869.2008.00714.x

Wenk, G. L. (2004). Assessment of spatial memory using the radial arm maze and Morris water maze. Curr. Protoc. Neurosci. Chapter 8, Unit 8.5A. doi: 10.1002/0471142301.ns0805as26

Wesensten, N. J., Balkin, T. J., and Belenky, G. (1999). Does sleep fragmentation impact recuperation? A review and reanalysis. J. Sleep Res. 8, 237-245. doi: 10.1046/j.1365-2869.1999.00161.x

Wesensten, N. J., Balkin, T. J., and Belenky, G. L. (1996). Effects of daytime administration of zolpidem and triazolam on performance. Aviat. Space Environ. Med. $67,115-120$.

Wesensten, N. J., Balkin, T. J., Reichardt, R. M., Kautz, M. A., Saviolakis, G. A., and Belenky, G. (2005). Daytime sleep and performance following a zolpidem and melatonin cocktail. Sleep 28, 93-103.

Whitman, D. B., Cox, C. D., Breslin, M. J., Brashear, K. M., Schreier, J. D., Bogusky, M. J., et al. (2009). Discovery of a potent, CNS-penetrant orexin receptor antagonist based on an n,n-disubstituted-1,4-diazepane scaffold that promotes sleep in rats. ChemMedChem 4, 1069-1074. doi: 10.1002/cmdc.200900069

Winrow, C. J., Gotter, A. L., Cox, C. D., Tannenbaum, P. L., Garson, S. L., Doran, S. M., et al. (2012). Pharmacological characterization of MK-6096 - a dual orexin receptor antagonist for insomnia. Neuropharmacology 62, 978-987. doi: 10.1016/j.neuropharm.2011.10.003

Zammit, G., Wang-Weigand, S., and Peng, X. (2008). Use of computerized dynamic posturography to assess balance in older adults after nighttime awakenings using zolpidem as a reference. BMC Geriatr. 8:15. doi: 10.1186/1471-231 8-8-15

Zanin, K. A., Patti, C. L., Sanday, L., Fernandes-Santos, L., Oliveira, L. C., Poyares, D., et al. (2013). Effects of zolpidem on sedation, anxiety, and memory in the plus-maze discriminative avoidance task. Psychopharmacology 226, 459-474. doi: $10.1007 / \mathrm{s} 00213-012-2756-3$

Conflict of Interest Statement: The authors declare that the research was conducted in the absence of any commercial or financial relationships that could be construed as a potential conflict of interest.

Received: 23 November 2013; accepted: 06 January 2014; published online: 31 January 2014.

Citation: Morairty SR, Wilk AJ, Lincoln WU, Neylan TC and Kilduff TS (2014) The hypocretin/orexin antagonist almorexant promotes sleep without impairment of performance in rats. Front. Neurosci. 8:3. doi: 10.3389/fnins.2014.00003

This article was submitted to Neuropharmacology, a section of the journal Frontiers in Neuroscience.

Copyright (๑) 2014 Morairty, Wilk, Lincoln, Neylan and Kilduff. This is an openaccess article distributed under the terms of the Creative Commons Attribution License (CC BY). The use, distribution or reproduction in other forums is permitted, provided the original author(s) or licensor are credited and that the original publication in this journal is cited, in accordance with accepted academic practice. No use, distribution or reproduction is permitted which does not comply with these terms. 